\title{
Evaluation of MiR-1908-3p as a novel serum biomarker for breast cancer and analysis its oncogenic function and target genes
}

Youzhi Zhu' ${ }^{1+}$, Qingshui Wang ${ }^{2,3+}$, Yun Xia ${ }^{2}$, Xiaoxue Xiong ${ }^{2}$, Shuyun Weng ${ }^{2}$, Huizhen $\mathrm{Ni}^{2}$, Yan Ye ${ }^{2}$, Ling Chen ${ }^{1}$, Junyu Lin', Yajuan Chen ${ }^{2}$, Haitao Niu' ${ }^{2}$ Xiangjin Chen ${ }^{1 *}$ and Yao Lin ${ }^{2^{*}}$

\begin{abstract}
Background: Breast cancer is one of the most common tumors for women globally. Various miRNAs have been reported to play a crucial role in breast cancer, however the clinical significance of miR-1908-3p in breast cancer remains unclear. The present study aimed to explore the role of miR-1908-3p in breast cancer.

Methods: The expression of miR-1908-3p was detected in 50 pairs of breast cancer tissues and adjacent normal tissues, 60 breast cancer patient serum and 60 healthy volunteer serum. The functional roles of miR-1908-3p in breast cancer cells such as proliferation, migration and invasion were evaluated using CCK8, SRB, wound healing and transwell chambers. In addition, bioinformatics tools were used to identify potential targets of miR-1908-3p.

Results: The results showed that the expression of miR-1908-3p were increased in breast cancer tissues and serum compared with normal breast tissues and serum of healthy volunteers respectively. Furthermore, the young breast cancer patients and HER2-positive patients had a higher level of tissues' miR-1908-3p than elder breast cancer patients and HER2-negative patients, respectively. The young breast cancer patients had a higher level of serum miR-1908-3p than elder breast cancer patients, ROC analysis suggested that miR-1908-3p had the potential as a promising serum diagnostic biomarker of breast cancer. Up-regulation of miR-1908-3p promoted the cells proliferation, migration and invasion while knockdown of miR-1908-3p inhibited these processes in breast cancer cell MCF-7 and MDA-MB-231. The potential target genes of miR-1908-3p in breast cancer included ID4, LTBP4, GPM6B, RGMA, EFCAB1, ALX4, OSR1 and PPARA. Higher expression of these eight genes correlated with a better prognosis for breast cancer patients.
\end{abstract}

Conclusions: These results suggest that miR-1908-3p may exert its oncogenic functions via suppression of these eight genes in breast cancer.

Keywords: Breast cancer, miR-1908-3p, Proliferation, Migration, Invasion

\footnotetext{
* Correspondence: rjbhcxj@fjmu.edu.cn; yaolin@fjnu.edu.cn

${ }^{\dagger}$ Youzhi Zhu and Qingshui Wang contributed equally to this work.

'Department of Thyroid and Breast Surgery, The First Affiliated Hospital of

Fujian Medical University, Fuzhou, China

${ }^{2}$ Key Laboratory of OptoElectronic Science and Technology for Medicine of

Ministry of Education, College of Life Sciences, Fujian Normal University,

Fuzhou, China

Full list of author information is available at the end of the article
}

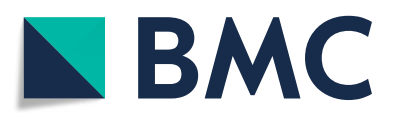

(- The Author(s). 2020 Open Access This article is licensed under a Creative Commons Attribution 4.0 International License, which permits use, sharing, adaptation, distribution and reproduction in any medium or format, as long as you give appropriate credit to the original author(s) and the source, provide a link to the Creative Commons licence, and indicate if changes were made. The images or other third party material in this article are included in the article's Creative Commons licence, unless indicated otherwise in a credit line to the material. If material is not included in the article's Creative Commons licence and your intended use is not permitted by statutory regulation or exceeds the permitted use, you will need to obtain permission directly from the copyright holder. To view a copy of this licence, visit http://creativecommons.org/licenses/by/4.0/. The Creative Commons Public Domain Dedication waiver (http://creativecommons.org/publicdomain/zero/1.0/) applies to the data made available in this article, unless otherwise stated in a credit line to the data. 


\section{Background}

Breast cancer is both the most commonly diagnosed cancer and the commonest cause of cancer death among women, which accounts for 630,000 deaths worldwide in 2018 [1]. Despite advances in early detection and development of new therapeutic targets. Although the survival rate of patients with breast cancer has improved, the five-year recurrence rate and five-year survival rate for breast cancer patients with metastases remain high. Therefore, the discovery of new molecular participants in the progress of breast cancer is essential to improve the diagnosis and treatment of breast cancer.

Previous research indicated that numerous miRNAs are involved in the progress of breast cancer [2-7]. MiRNAs are a type of non-coding RNAs containing 21-25 nucleotides, and function as gene regulators by binding to target genes and inhibiting translation [8]. Many of these target genes are involved in fundamental biological processes such as cells differentiation, cells proliferation and cells migration [9-12]. The dysregulated miRNAs play a key role in tumorigenesis and tumor development and are related to poor prognosis in various carcinomas [13-15]. Previous studies have revealed that miR-1908 is an oncogene in glioblastoma [16]. In addition, miR-1908 is also associated with the prognosis of various tumors, such as osteosarcoma [17], hepatoma [18] and glioma [19]. However, the expression, functional roles and target genes of miR-1908-3p in breast cancer progression has not yet been studied.

In this work, miR-1908-3p expression was examined in tissues, TCGA database and the serum of breast cancer patients. The functional roles of miR-1908-3p were also studied. In addition, screening and enrichment analysis of miR-1908-3p target genes were performed to analyze the potential regulatory mechanisms of miR1908-3p function.

\section{Methods}

\section{Collection of clinical tissues and serum}

The research was composed of 50 breast cancer fresh tissue samples (range from 28 to 83 years) and 50 adjacent breast normal tissue samples who underwent surgical resections at the first affiliated hospital of Fujian medical university between April 2018 and June 2019. The specimens of this study were diagnosed as breast cancer tissues by pathological diagnosis. The extracted samples were immediately placed in liquid nitrogen and then stored at $-80^{\circ} \mathrm{C}$. A total of 60 breast cancer patient serum samples (range from 26 to 81 years) and 60 healthy control serum samples were collected from The
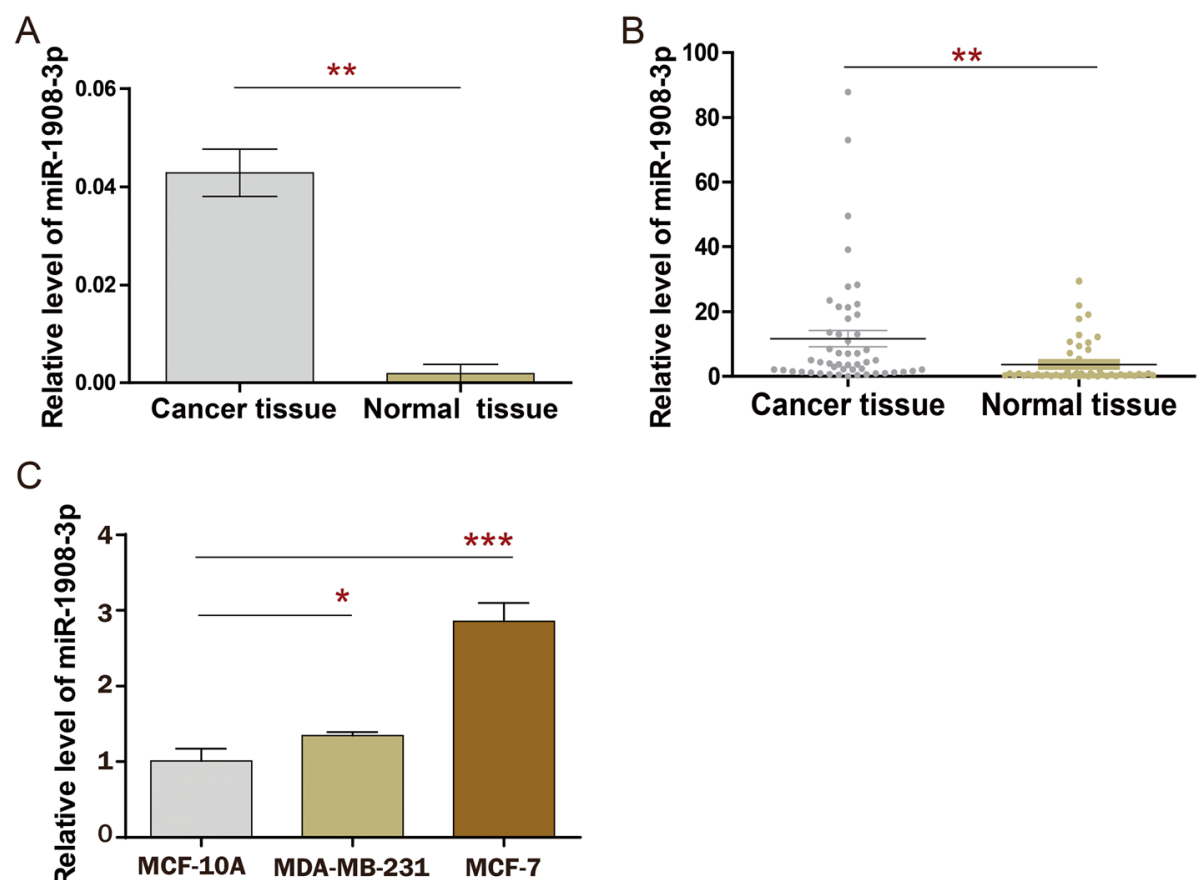

Fig. 1 MiR-1908-3p is highly expressed in breast cancer tissues and breast cancer cells. a The miR-1908-3p expression level in breast cancer tissues and adjacent normal breast tissues were compared using TCGA. b The miR-1908-3p expression level in 50 pairs of fresh breast cancer tissue and adjacent normal tissue was determined by RT-qPCR. Quantification of miR-1908-3p expression were calculated with the 2- $\Delta$ Ct method. c The expression of miR-1908-3p in two breast cancer cell lines and the non-transformed mammary epithelial MCF-10A was determined by RTqPCR. Relative quantification of miR-1908-3p expression were calculated with the 2 - $\Delta \Delta \mathrm{Ct}$ method. ${ }^{*}, p<0.05 ;{ }^{* *}, p<0.01 ;{ }^{* * *}, p<0.001$ 
First Affiliated Hospital of Fujian Medical University. This study was performed with the approval of the Ethics Committee of the first affiliated hospital of Fujian Medical University and complied with the Helsinki Declaration. All patients and healthy volunteers have signed written informed consent.

\section{Cell culture and transfection}

MCF-10A (normal epithelial cell line), MCF-7(Human breast cancer cell line) and MDA-MB-231(Human breast cancer cell line) were obtained from the ATCC (Manassas, VA, USA). All cells were cultured in Dulbecco's modified Eagle's medium containing $10 \%$ fetal bovine serum and then incubated at $37^{\circ} \mathrm{C}$ in a 5\% CO2 environment. These cells underwent mycoplasma testing and STR analyses. Lipofectamine 2000 (Invitrogen, Carlsbad, CA, USA) was used for miRNA transfection experiments [20]. Human breast cancer cell lines MCF-7 and MDA-MB-231 were divided into three groups: control (NC), miR-1908-3pmimic, miR-1908-3p-inhibitor. miR-1908-3p-mimic and miR-1908-3p-inhibitor were synthesized by GenePharma company (Shanghai, China, Cat. No. B03001 \& B01001).

\section{RNA extraction and real-time polymerase chain reaction}

Trizol reagent (Invitrogen, Carlsbad, CA, USA) was used for RNA extraction experiments. The TaqMan MicroRNA Reverse Transcription Kit (Takara, Otsu, Japan) was then used to synthesize cDNA [21]. Real-Time PCR was performed on Applied Biosystems StepOne Plus Real-Time PCR System (Takara, Otsu, Japan) with the PowerUp SYBR Master Mix kit (Thermo Fisher, Shanghai, China,), and the following cycling conditions: $95^{\circ} \mathrm{C}$ $10 \mathrm{~min}, 40$ cycles of $95^{\circ} \mathrm{C}, 30 \mathrm{~s} ; 57^{\circ} \mathrm{C}, 5 \mathrm{~s} ; 72^{\circ} \mathrm{C}, 15 \mathrm{~s}$. In the detection of miRNA in serum samples, a synthetic elegans nematode miRNA (cel-miRNA-39) was used as an internal control due to the lack of universal endogenous controls. Detailed primer sequence information is listed in Additional file 1.

\section{Cell proliferation assay}

MCF-7 and MDA-MB-231 cells were cultured in a culture plate at a density of 5000 cells per well. After $24 \mathrm{~h}$ of incubation, compounds of various concentrations were added to the cell culture medium, and cultured for another $72 \mathrm{~h}$. The CCK8 or SRB assay is used to determine cell proliferation [22].

\section{Transwell invasion chamber experiment and cell migration experiment}

The scratch assay was used to detect the migration of MDA-MB-231 cells and MCF-7 cells. In this experiment, when the degree of cell fusion after transfection was
$80 \%$, a $100 \mu \mathrm{l}$ pipette tip was used for scraping. After washing with PBS, the wound closure was observed, and the cells migration rate was calculated by the ratio of the surface area of the migrated cells to the total surface area.

The Transwell chamber was used to detect the invasion of MDA-MB-231 cells and MCF-7 cells. In this experiment, cells were cultured in an insertion chamber (Corning) with a Matrigel-coated membrane. After the cells were fixed and stained with $0.1 \%$ crystal violet, five random fields of each group were selected under the microscope and counted.

Table 1 Clinicopathological variables and the expression of miR-1908-3p in the breast cancer tissues

\begin{tabular}{|c|c|c|c|}
\hline Variable & Number & $\begin{array}{l}\text { Mean of miR- } \\
\text { 1908-3p expression }\end{array}$ & $p$ value \\
\hline Age & & & $<0.05$ \\
\hline$\leq 40$ & $25(50 \%)$ & 14.89 & \\
\hline$>40$ & $25(50 \%)$ & 5.54 & \\
\hline metastasis & & & 0.25 \\
\hline Negative & $21(42 \%)$ & 6.83 & \\
\hline Positive & $29(58 \%)$ & 12.66 & \\
\hline Grade & & & 0.54 \\
\hline 1 & $3(6 \%)$ & 12.49 & \\
\hline 2 & $21(42 \%)$ & 6.97 & \\
\hline 3 & $26(52 \%)$ & 12.57 & \\
\hline TNM & & & 0.66 \\
\hline$|/| \mid$ & $36(72 \%)$ & 9.53 & \\
\hline III/IV & $14(28 \%)$ & 11.95 & \\
\hline Tumor size & & & 0.84 \\
\hline$\leq 2$ & $20(40 \%)$ & 8.39 & \\
\hline$>2, \leq 5$ & $28(56 \%)$ & 11.33 & \\
\hline$>5$ & $2(4 \%)$ & 12.68 & \\
\hline ER statue & & & 0.41 \\
\hline Negative & $16(32 \%)$ & 7.24 & \\
\hline Positive & $34(68 \%)$ & 11.61 & \\
\hline PR statue & & & 0.3 \\
\hline Negative & 19 (38\%) & 6.36 & \\
\hline Positive & $31(62 \%)$ & 12.22 & \\
\hline HER-2 & & & $<0.01$ \\
\hline Negative & $35(70 \%)$ & 5.59 & \\
\hline Positive & 15 (30\%) & 20.98 & \\
\hline Molecular Subtype & & & 0.65 \\
\hline luminal & $34(68 \%)$ & 11.61 & \\
\hline her-2+ & $8(16 \%)$ & 9.14 & \\
\hline Triple-negative & $8(16 \%)$ & 5.34 & \\
\hline
\end{tabular}

Abbreviations: $E R$ estrogen receptor, $P R$ progesterone receptor, HER-2 human epidermal growth factor receptor 2 


\section{Bioinformatics analysis}

TargetScan website (http://www.Targetscan.org/) was used to predict potential target genes for miR-1908-3p [23-26]. The expression of potential target genes for miR-1908-3p in breast cancer were obtained from GEPIA website (http://gepia.cancer-pku.cn/index.html) [27]. The prognosis of miR-1908-3p and potential target genes for miR-1908-3p were obtained from KaplanMeier Plotter website (http://kmplot.com/) [28].

\section{Statistical analysis}

Data were analyzed using Prism 5.0 software (Graphpad Software, Inc., La Jolla, CA, USA). Quantification of miR-1908-3p level in breast cancer tissues and serum were calculated with the $2^{-\Delta \mathrm{Ct}}$ method. Relative quantification of miR-1908-3p expression in breast cancer cell lines was calculated with the $2^{-\Delta \Delta \mathrm{Ct}}$ method. The difference of the two lines was calculated using the Grouped analyses (Two-way ANOVA). Receiver operating characteristics (ROC) curve analysis was used to analyze the ability of miR-1908-3p as a serum biomarker for breast cancer patients. A $p$ value of $<0.05$ indicates statistical significance.

\section{Results}

\section{Upregulation of miR-1908-3p in breast cancer}

In order to explore the expression pattern of miR-1908$3 \mathrm{p}$ in breast cancer, TCGA dataset was selected for initial screening. Analysis using TCGA data showed that the level of miR-1908-3p was significantly higher in breast cancer tissues than that in normal breast tissues (Fig. 1a, $p<0.01$ ). Additionally, detection in the 50 breast cancer tissues samples and 50 matched adjacent normal breast tissues samples further confirmed that miR-1908$3 p$ levels were increased in breast cancer (Fig. $1 \mathrm{~b}, p<$ $0.01)$. Compared to the normal breast cancer cell line MCF-10A, miR-1908-3p levels were also found to be enhanced in two breast cancer cell lines MCF-7 and MDA-MB-231 (Fig. 1c). The correlations between patients' clinical characteristics and the levels of miR-1989$3 \mathrm{p}$ in tissues are summarized in Table 1. Only age and her-2 status were significantly associated with miR1908-3p expression in cancer tissues. The breast cancer patients with Age $\leq 40$ or positive her- 2 status have higher miR-1908-3p levels. Moreover, the expression of miR-1908-3p was significantly higher in the serum of 60 breast cancer patients compared to 60 healthy donors (Fig. 2a). The area under the curve (AUC) of the serum miR-1908-3p was 0.838 (Fig. 2b), suggesting serum miR1908-3p expression might be a new serum biomarker for breast cancer identification. In addition, the correlations between patients' clinical characteristics and serum levels of miR-1989-3p are summarized in Table 2. Only age was significantly associated with the miR-1908-3p levels in serum. The breast cancer patients with Age $\leq$ 40 have higher serum level of miR-1908-3p.

miR-1908-3p promoted the proliferation, migration, and invasion of breast cancer MCF-7 cells

In order to study the biological function of miR-1908-3p in breast cancer cells, miR-1908-3p mimics, miR-1908-3p inhibitors and miR-1908-3p negative control (miR-1908$3 \mathrm{p}-\mathrm{NC}$ ) were separately transfected into MCF-7 cells. As presented in Fig. 3a, transfection of miR-1908-3p mimic increased miR-1908-3p level, whereas miR-1908-3p inhibitors significantly inhibited miR-1908-3p level in MCF-7

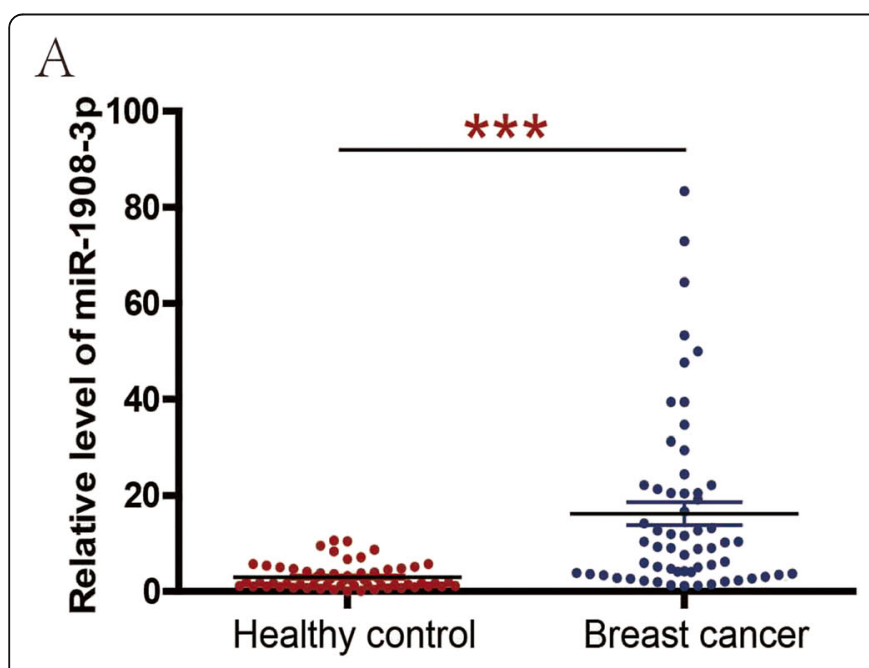

\section{B}

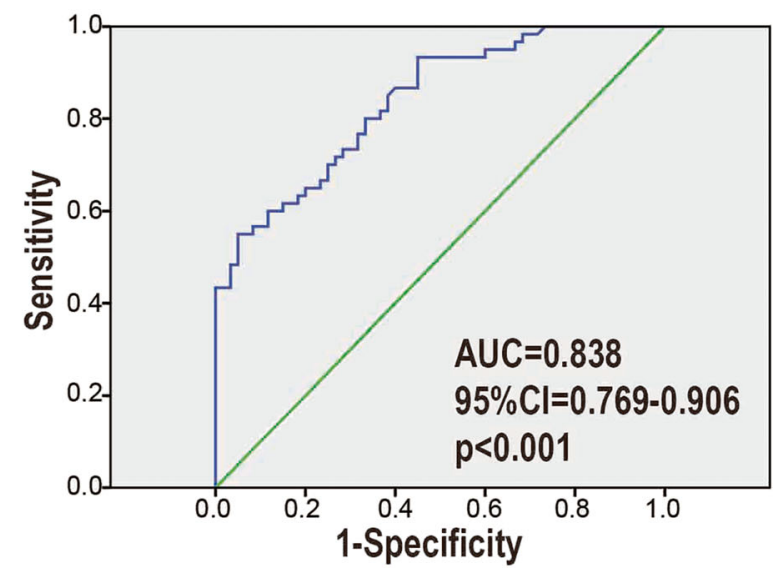

Fig. 2 Serum miR-1908-3p level is increased in breast cancer patients compared with healthy donors. a The serum miR-1908-3p level in 60 breast cancer patients and 60 healthy donors were determined by RT-qPCR. Quantification of miR-1908-3p expression were calculated with the 2- $\triangle$ Ct method. b High levels of serum miR-1908-3p as a diagnostic marker in patients with breast cancer based on 60 breast cancer patients and 60 healthy donors.***, $p<0.001$ 
Table 2 Clinicopathological variables and the expression of miR-1908-3p in the serum of breast cancer

\begin{tabular}{|c|c|c|c|}
\hline Variable & Number & $\begin{array}{l}\text { Mean of miR- } \\
1908-3 p \text { expression }\end{array}$ & $p$ value \\
\hline Age & & & $<0.001$ \\
\hline$\leq 40$ & 27 (45\%) & 30.41 & \\
\hline$>40$ & $33(55 \%)$ & 5.18 & \\
\hline Metastasis & & & 0.723 \\
\hline Negative & $25(42 \%)$ & 15.42 & \\
\hline Positive & $35(58 \%)$ & 17.33 & \\
\hline Grade & & & 0.086 \\
\hline 1 & $11(18 \%)$ & 15.77 & \\
\hline 2 & $20(33 \%)$ & 9.01 & \\
\hline 3 & $29(49 \%)$ & 22.00 & \\
\hline TNM & & & 0.072 \\
\hline$|/| \mid$ & $46(77 \%)$ & 16.00 & \\
\hline III/IV & $14(23 \%)$ & 18.26 & \\
\hline Tumor size & & & 0.721 \\
\hline$\leq 2$ & $22(37 \%)$ & 15.46 & \\
\hline$>2, \leq 5$ & $35(58 \%)$ & 16.42 & \\
\hline$>5$ & $3(5 \%)$ & 25.73 & \\
\hline ER statue & & & 0.65 \\
\hline Negative & 19 (32\%) & 18.29 & \\
\hline Positive & $41(68 \%)$ & 15.72 & \\
\hline PR statue & & & 0.418 \\
\hline Negative & $22(37 \%)$ & 19.36 & \\
\hline Positive & $38(63 \%)$ & 14.89 & \\
\hline HER-2 & & & 0.489 \\
\hline Negative & $52(87 \%)$ & 15.81 & \\
\hline Positive & $8(13 \%)$ & 21.22 & \\
\hline Molecular Subtype & & & 0.786 \\
\hline luminal & $41(68 \%)$ & 15.72 & \\
\hline her-2+ & $5(8 \%)$ & 14.86 & \\
\hline triple-negative & $14(24 \%)$ & 19.79 & \\
\hline
\end{tabular}

Abbreviations: $E R$ estrogen receptor, $P R$ progesterone receptor, HER-2 human epidermal growth factor receptor 2

cells. CCK8 and SRB were applied to explore the function of miR-1908-3p on breast cancer cell proliferation. The results showed that upregulation of miR-1908-3p increased MCF-7 cells proliferation, while down-regulation of the miR-1908-3p level attenuated MCF-7 cells proliferation (Fig. 3b \& c). MCF-7 cells migration and invasion were determined by wound healing and transwell assays. As presented in Fig. 3d, miR-1908-3p mimics promoted the MCF-7 cells migration, while MCF-7 cells migration was suppressed by miR-1908-3p inhibitors. Meanwhile, miR-1908-3p mimics promoted MCF-7 cells invasion, while MCF-7 cells invasion was suppressed by miR-1908$3 p$ inhibitors (Fig. 3e).

miR-1908-3p promoted the proliferation, migration, and invasion of breast cancer MDA-MB-231 cells

At the same time, miR-1908-3p mimics, miR-1908-3p inhibitors and miR-1908-3p negative control (miR1908-3p-NC) were also separately transfected into MDA-MB-231 cells. As presented in Fig. 4a, transfection of miR-1908-3p mimic increased miR-1908-3p level, whereas miR-1908-3p inhibitors significantly inhibited miR-1908-3p level in MDA-MB-231 cells. The results of CCK8 and SRB showed that upregulation of miR-1908-3p increased MDA-MB-231 cells proliferation, while down-regulation of the miR-1908$3 p$ level attenuated MDA-MB-231 cells proliferation (Fig. 4b \& c). MDA-MB-231 cells migration and invasion were determined by wound healing and transwell assays. As presented in Fig. 4d, miR-1908-3p mimics promoted MDA-MB-231 cells migration, while MDAMB-231 cells migration were suppressed by miR1908-3p inhibitors. Meanwhile, miR-1908-3p mimics promoted MDA-MB-231 cells invasion, while MDAMB-231 cells invasion owere suppressed by miR1908-3p inhibitors (Fig. 4e). Taken together, these results revealed that the increased level of miR-1908$3 p$ promoted breast cancer cells proliferation, migration, and invasion.

\section{Exploration of miR-1908-3p target genes}

To investigate the possible regulation mechanisms of miR-1908-3p, we utilized an online bio-informatics database Targetscan to select possible miR-1908-3p target genes. A total of 480 targeted genes were predicted by Targetscan (Fig. 5a). For better understanding of these genes, GO function and KEGG pathway enrichment analysis were performed. GO functional annotation includes molecular function (MF), cellular component (CC) and biological process (BP). The top 10 enriched GO items were listed in Fig. 5b-d. In the MF of GO analysis, these genes were significantly enriched in sequence-specific DNA binding, transcriptional activator activity, RNA polymerase II core promoter proximal region sequence-specific binding, RNA polymerase II core promoter proximal region sequence-specific DNA binding, protein dimerization activity and protein-cysteine Spalmitoyltransferase activity (Fig. 5b). For CC analysis, these genes were significantly enriched in nucleus, transcription factor complex, protein-DNA complex, microtubule and neuronal cell body (Fig. 5c). BP analysis demonstrated that these target genes were significantly enriched in transcription from RNA polymerase II promoter, positive regulation of transcription from RNA polymerase II promote, inner ear morphogenesis, 

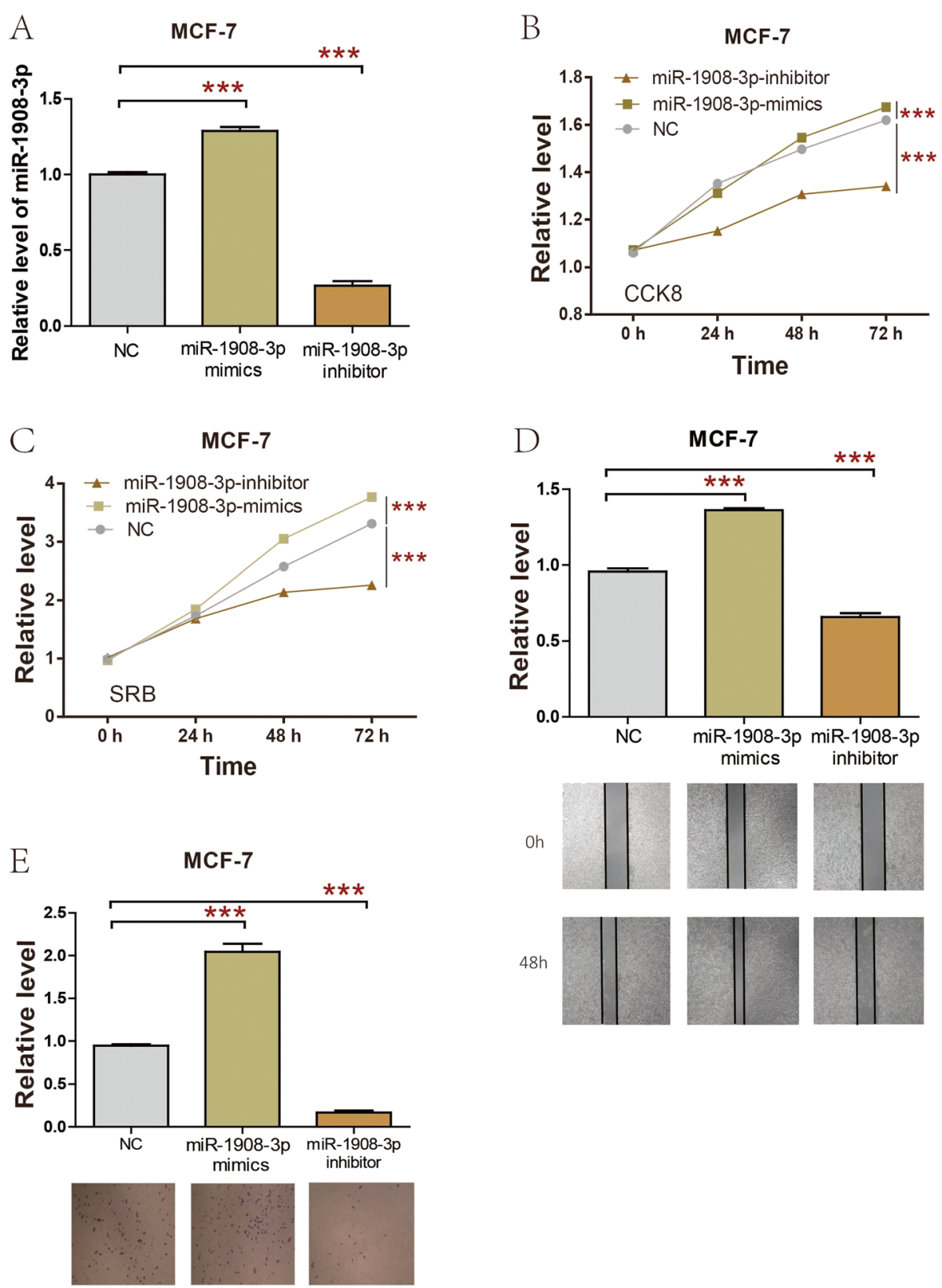

Fig. 3 miR-1908-3p promotes MCF-7 cell proliferation, migration and invasion. a The expression of miR-1908-3p in MCF-7 cell were affected by transfection of miR-1908-3p mimics or inhibitor. b \& c CCK8 and SRB assay were used to evaluated the proliferation of MCF-7 cells following transfection with miR-1908-3p mimics or inhibitor. $\mathbf{d}$ The migration ability of MCF-7 cells with miR-1908-3p mimics or inhibitor transfection. e The invasion ability of MCF-7 cells with miR-1908-3p mimics or inhibitor transfection. Relative quantification of miR-1908-3p expression were calculated with the $2-\Delta \Delta \mathrm{Ct}$ method. ${ }^{* *}, p<0.001$

negative regulation of transcription from RNA polymerase II promoter and regulation of transcription, DNAtemplated (Fig. 5d). The result of KEGG pathway enrichment analysis showed that these genes were mostly enriched in endometrial cancer, viral carcinogenesis, endocytosis, amino sugar and nucleotide sugar metabolism and choline metabolism in cancer (Fig. 5e).
It is well known that much evidence supports the negative correlation between expression of miRNAs and target genes. We first identified DEGs (different expression genes) between breast cancer samples and normal breast samples using GSE33447 database (Fig. 6a). Subsequently, 1192 up-regulated mRNAs and 786 downregulated mRNAs were identified. After conducting a 


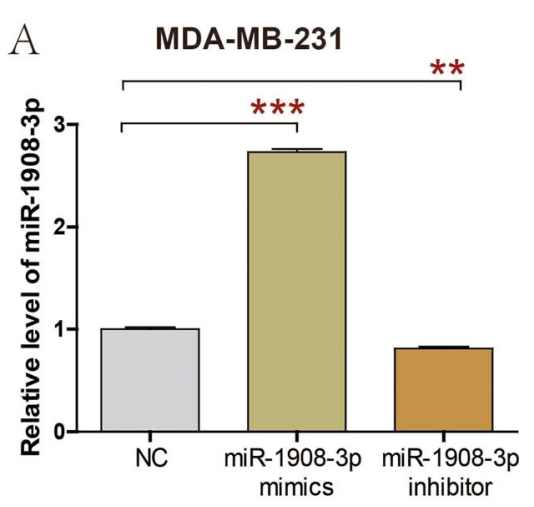

\section{B MDA-MB-231}

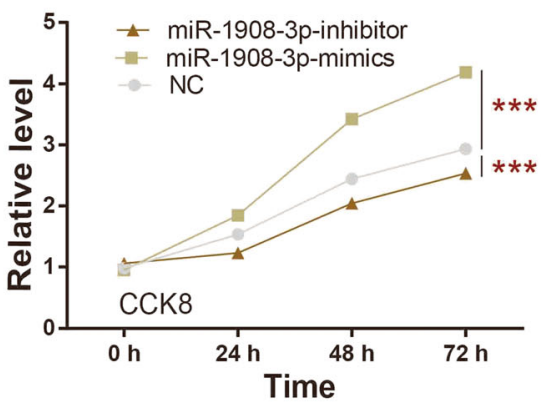

D

MDA-MB-231

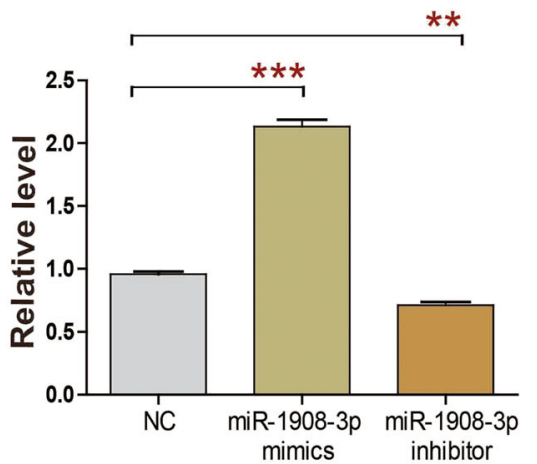

Oh
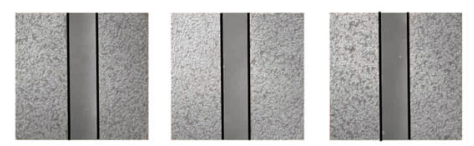

$48 \mathrm{~h}$
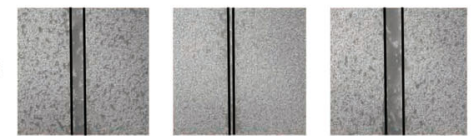

Fig. 4 miR-1908-3p promotes MDA-MB-231 cell proliferation, migration and invasion. a The expression of miR-1908-3p in MDA-MB-231 cell were affected by transfection of miR-1908-3p mimics or inhibitor. b \& c CCK8 and SRB assay were used to evaluated the proliferation of MDA-MB-231 cells following transfection with miR-1908-3p mimics or inhibitor. $\mathbf{d}$ The migration ability of MDA-MB-231 cells with miR-1908-3p mimics or inhibitor transfection. e The invasion ability of MDA-MB-231 cells with miR-1908-3p mimics or inhibitor transfection. Relative quantification of miR1908-3p expression were calculated with the $2-\Delta \Delta C \mathrm{Ct}$ method. ${ }^{*}, p<0.05 ;{ }^{* *}, p<0.01 ;{ }^{* * *}, p<0.001$

combined analysis of down-regulated mRNAs and target genes of miR-1908-3p, we further identified $13 \mathrm{miR}-$ 1908-3p target genes with down-regulated mRNAs in breast cancer samples. These genes were ID4 (inhibitor of DNA binding 4), LTBP4 (latent transforming growth factor beta binding protein 4), CCNB1IP1 (cyclin B1 interacting protein 1), GPM6B (glycoprotein M6B), RGMA (repulsive guidance molecule family member a), BEGAIN (brain-enriched guanylate kinase-associated), EFCAB1 (EF-hand calcium binding domain 1), ALX4 (ALX homeobox 4), TRIOBP (TRIO and F-actin binding protein), OSR1 (odd-skipped related transciption factor), 


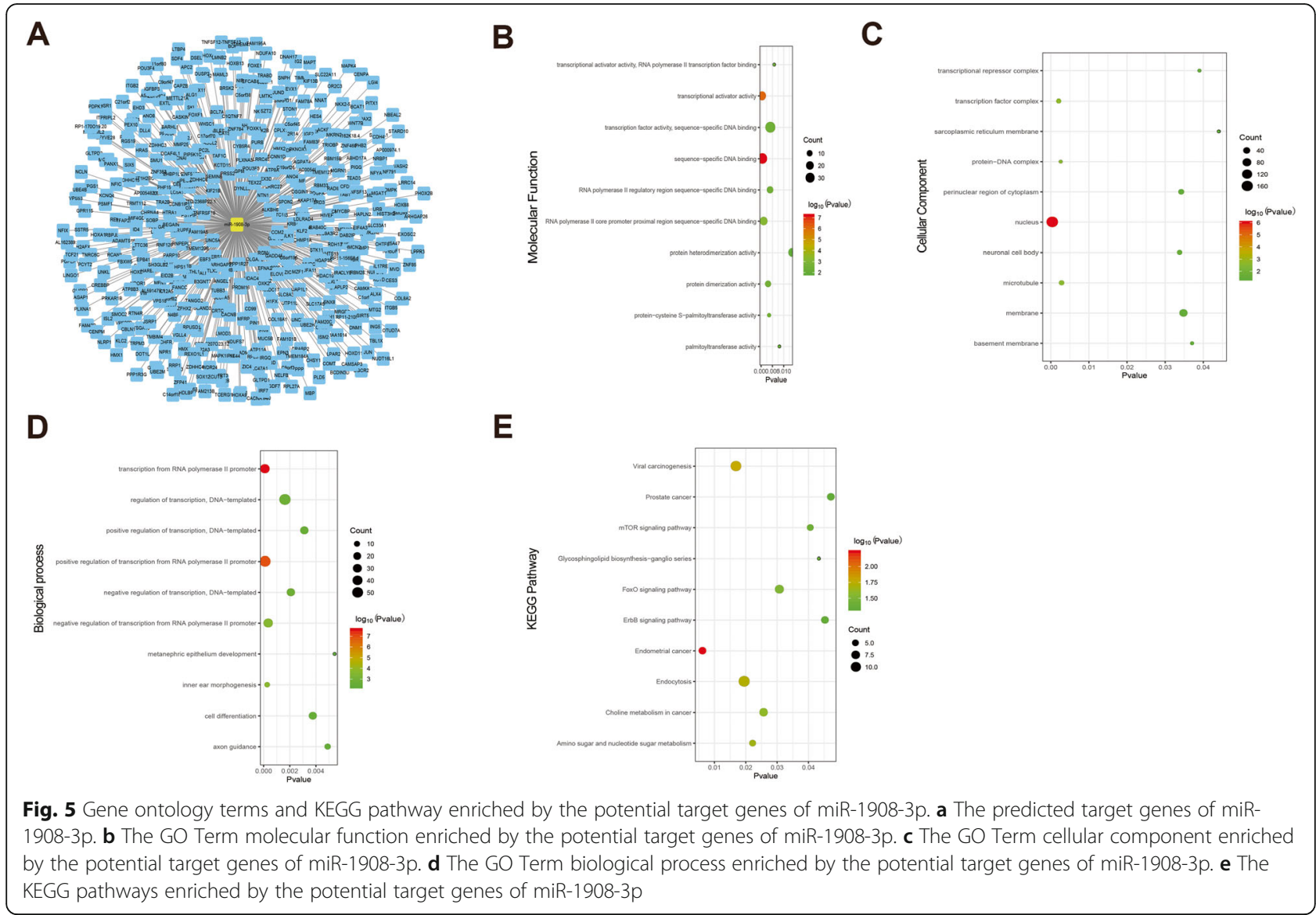

ANO4 (anoctamin 4), PPARA (peroxisome proliferatoractivated) and ZDHHC15 (zinc finger, DHHC-type containing 15). Subsequently, GEPIA database was used to detect the expression levels of these 13 genes in breast cancer. As shown in Fig. 6c-o, the levels of eight of the 13 genes were significantly lower in breast cancer tissues than those in normal breast tissues. The expression analysis of CCNB1IP1, BEGAIN, TRIOBP, ANO4 and ZDHHC15 demonstrated no significant difference between breast cancer and normal breast samples. At the same time, the up-regulated expression of ID4, LTBP4, GPM6B, RGMA, EFCAB1, ALX4, OSR1 and PPARA in breast cancer tissues were also observed in GSE33447 (Additional file 2). The prognostic roles of these 8 genes and miR-1908 in breast cancer were evaluated using Kaplan-Meier Plotter website. As shown in Fig. 7a-i, the higher expression of miR-1908 indicated a worse prognosis whereas the higher expression of ID4, LTBP4, GPM6B, RGMA, EFCAB1, ALX4, OSR1 and PPARA correlated with a better prognosis in breast cancer. Based on these findings, a potential miR-1908-3p-mRNA regulatory network, miR-1908-3P-ID4/ LTBP4/ GPM6B/ RGMA/ EFCAB1/ ALX4/ OSR1/ PPARA, contributing to breast cancer onset and progression could be established.

\section{Discussion}

Previous studies have revealed that miR-1908 is abnormally expressed in some malignancies, including glioma, osteosarcoma and liver cancer. The level of miR-1908 was increased and correlated with poor prognosis of glioma patients. The increased level of miR-1908 is not only strongly associated with cell proliferation and migration, but also poor prognosis of osteosarcoma patients. In contrast with its role as an oncogene in glioma and osteosarcoma, miR-1908 may act as a tumor suppressor in liver cancer by targeting MARK1 (Microtubule affinity-regulating kinase 1) signaling pathway. In this research, increased level of miR-1908-3p was observed in breast cancer tissues compared with normal breast tissues, suggesting miR-1908-3p might serve as a diagnostic marker of breast cancer. Meanwhile, we found that the serum level of miR-1908-3p was upregulated in breast cancer patients compared with healthy volunteers. Furthermore, the young breast cancer patients and HER2-positive patients had a higher level of tissues' miR-1908-3p than elder breast cancer patients and HER2-negative patients, respectively. The young breast cancer patients had a higher level of serum miR-1908-3p than elder breast cancer patients, the serum level of miR-1908-3p exhibited great reliability in 


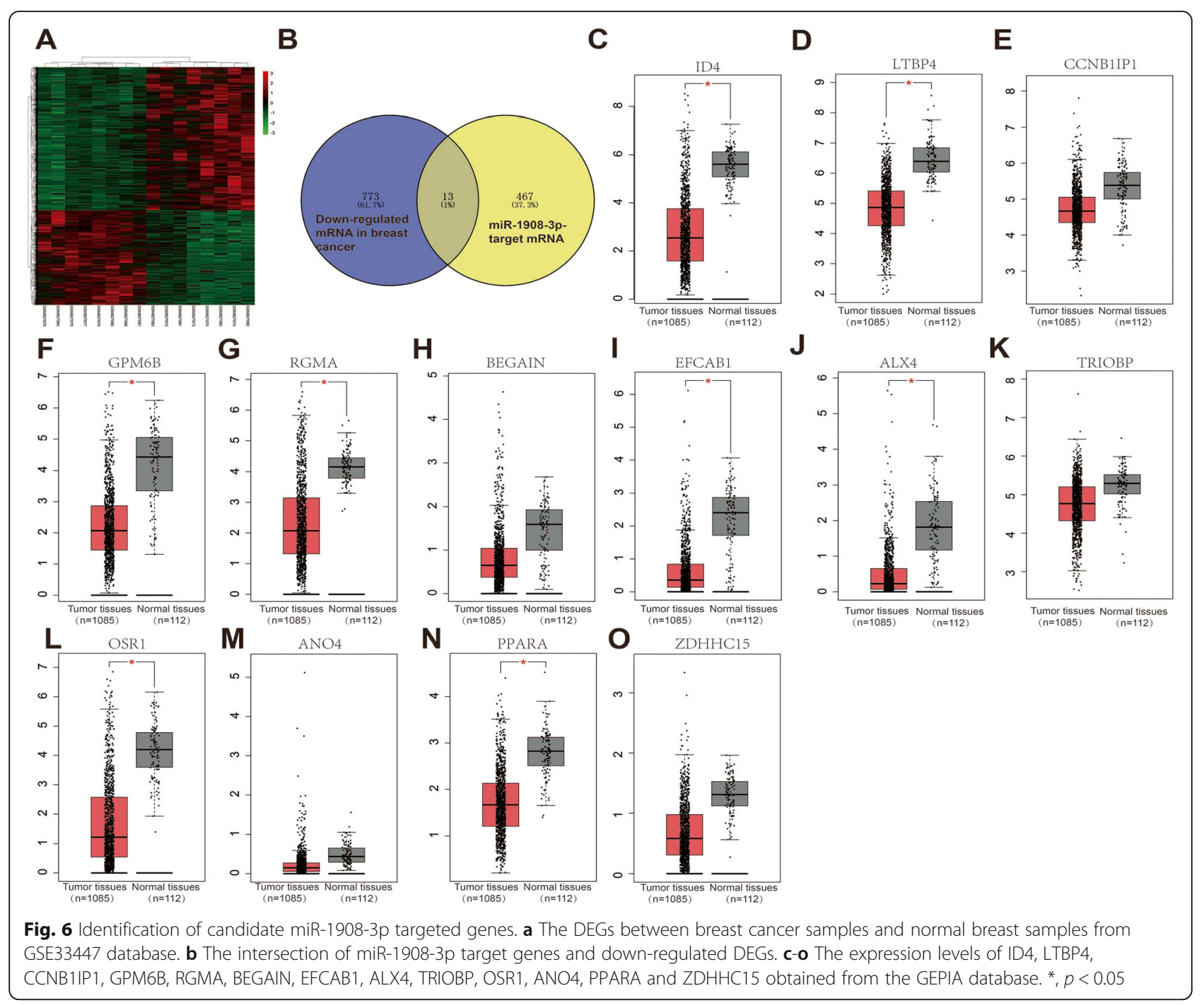

discriminating breast cancer in ROC curve analysis. Considering the number of serum samples in the study, further experiments with enlarged sample size were still needed to verify these results.

MiR-1908-3p is over-expressed in some breast cancer cell lines. We demonstrated that miR-1908-3p could promote breast cancer cell proliferation, invasion and migration, which supports its oncogenic function in breast cancer. MiRNAs play their roles by inhibiting the expression of multiple target mRNAs. Base on the known target gene database Targetscan, 480 mRNAs were predicted to be the target mRNAs for miR-1908$3 p$. The enriched results of KEGG pathways and GO analysis suggested that most potential target genes are significantly related to transcription. The trio of enriched KEGG pathways, the mTOR (mechanistic target of rapamycin) signaling pathway, FoxO (forkhead box $\mathrm{O}$ ) signaling pathway and ErbB signaling pathway. Due to the complex interactions between miRNAs and their target
mRNAs in vivo, one miRNA may target multiple mRNAs and target mRNAs are usually tissue specific. To test the predicting power and validate the potential target genes of miR-1908-3p in breast cancer, the mRNAs level of these 480 mRNAs were further checked by GEO data and TCGA data. Interestingly, eight genes (ID4, LTBP4, GPM6B, RGMA, EFCAB1, ALX4, OSR1 and PPARA) were confirmed to be down-expressed in breast cancer tissues, and associated with the overall survival time of breast cancer patients, as high expression of these genes correlate with an improved prognosis. These eight genes have greater possibility to be real target genes of miR-1908-3p in breast cancer cells. ID4 protein is a helix-loop-helix DNA binding factor that is involved in cell proliferation and differentiation [29]. The level of LTBP4 was decreased in breast cancer [30]. GPM6B is a membrane glycoprotein that is involved in intercellular communication and membrane transport. Previous studies have found that RGMA inhibits the 


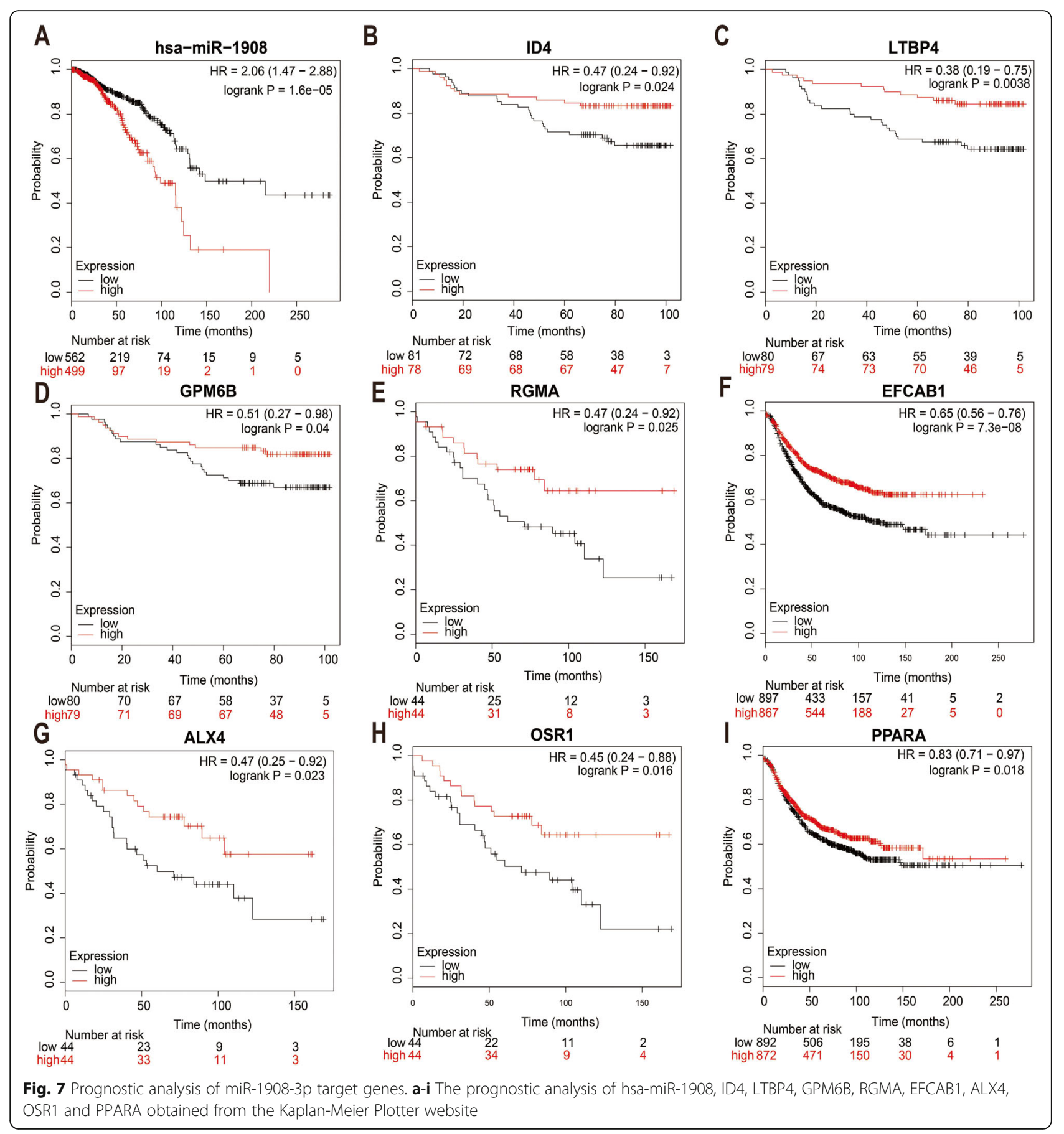

proliferation of oral squamous cell carcinoma (OSCC) cells, and the low expression of RGMA is closely related to the poor prognosis of patients with OSCC [31]. ALX4 expression was found to be decreased in breast cancer. Meanwhile, ALX4 inhibited breast cancer cell proliferation and metastasis [32]. OSR1 is a tumor suppressor that regulates the proliferation and invasion of renal cell carcinoma cells [33]. Low expression of PPARA is related to the proliferation, invasion and migration of hepatocellular carcinoma cells [34].

Previous research has shown that most of these eight genes act as tumor suppressor genes in multiple types of tumor, including breast cancer. Therefore, miR-1908-3p may target these eight genes to faciliate the progress of breast cancer and decrease the survival time of breast cancer patients. 


\section{Conclusions}

In summary, the current research suggested that miR1908-3p might promote the breast cancer cells proliferation and metastasis by suppressing eight genes (ID4, LTBP4, GPM6B, RGMA, EFCAB1, ALX4, OSR1 and PPARA) and the serum level of miR-1908-3p could be used as a diagnostic and predictive biomarker for breast cancer.

\section{Supplementary information}

Supplementary information accompanies this paper at https://doi.org/10. 1186/s12885-020-07125-4.

Additional file 1. Primer sequence used in RT-qPCR.

Additional file 2. The expression of eight genes in breast cancer. The expression of ID4 (A), LTBP4 (B), GPM6B (C), RGMA (D), EFCAB1 (E), ALX4 $(\mathrm{F})$, OSR1 (G) and PPARA $(\mathrm{H})$ in breast cancer based on GSE33447.

\begin{abstract}
Abbreviations
ID4: Inhibitor of DNA binding 4; LTBP4: Latent transforming growth factor beta binding protein 4; CCNB1IP1: Cyclin B1 interacting protein 1. GPM6B: Glycoprotein M6B; RGMA: Repulsive guidance molecule family member a; BEGAIN: Brain-enriched guanylate kinase-associated; EFCAB1: EFhand calcium binding domain 1; ALX4: ALX homeobox 4; TRIOBP: TRIO and F-actin binding protein; OSR1: Odd-skipped related transciption factor; ANO4: Anoctamin 4; PPARA: Peroxisome proliferator-activated; ZDHHC15: Zinc finger, DHHC-type containing 15; MARK1: Microtubule affinity-regulating kinase 1; mTOR: Mechanistic target of rapamycin; FoxO: Forkhead box O; TGFB: Transforming growth factor beta; OSCC: Oral squamous cell carcinoma
\end{abstract}

\section{Acknowledgements}

Not applicable.

\section{Authors' contributions}

$X C$ and $Y L$ contributed to the conception and design. $Y X, X X, S W$ and $Y Y$ contributed to the development of methodology. $Y Z$ and $Q W$ contributed to the writing, review, and/or revision of the manuscript. LC, HN, JL, YC and HN contributed to the study supervision. All authors read and approved the final manuscript.

\section{Funding}

This research was funded by Science and technology innovation joint fund project (2017Y9089), Training plan for young and middle-aged key talents (2019-ZQN-63): reagents purchasing and data analysis; The Engineering Technology Research Center of Characteristic Medicinal Plans of Fujian (PP201904) and the scientific research innovation program "Xiyuanjiang River Scholarship" of College of Life Sciences, Fujian Normal University: reagents purchasing.

\section{Availability of data and materials}

The datasets used and/or analyzed during the current study are available from the corresponding author on reasonable request.

\section{Ethics approval and consent to participate}

The study was approved by the Ethics Committee of the first affiliated hospital of Fujian Medical University and complied with the Helsinki Declaration. Written consents were obtained from all study participants.

\section{Consent for publication}

Not applicable.

\section{Competing interests}

The authors declare that they have no competing interests.

\section{Author details}

${ }^{1}$ Department of Thyroid and Breast Surgery, The First Affiliated Hospital of Fujian Medical University, Fuzhou, China. ${ }^{2}$ Key Laboratory of OptoElectronic Science and Technology for Medicine of Ministry of Education, College of Life Sciences, Fujian Normal University, Fuzhou, China. ${ }^{3}$ The Engineering Technology Research Center of Characteristic Medicinal Plants of Fujian, Ningde Normal University, Ningde, China.

Received: 18 February 2020 Accepted: 1 July 2020

Published online: 10 July 2020

\section{References}

1. Bray F, Ferlay J, Soerjomataram I, Siegel RL, Torre LA, Jemal A. Global cancer statistics 2018: GLOBOCAN estimates of incidence and mortality worldwide for 36 cancers in 185 countries. CA Cancer J Clin. 2018;68:394-424.

2. van den Berg M, Krauskopf J, Ramaekers J, Kleinjans J, Prickaerts J, Briedé J. Circulating microRNAs as potential biomarkers for psychiatric and neurodegenerative disorders. Prog Neurobiol. 2019:185:101732.

3. Lou W, Fan W. Construction of potential glioblastoma multiforme-related miRNA-mRNA regulatory network. Front Mol Neurosci. 2019;12:66.

4. Zhao H, Shen J, Medico L, Wang D, Ambrosone CB, Liu S. A pilot study of circulating miRNAs as potential biomarkers of early stage breast cancer. PLoS One. 2010;5:e13735.

5. Schrauder MG, Strick R, Schulz-Wendtland R, Strissel PL, Kahmann L, Loehberg CR, Lux MP, Jud SM, Hartmann A, Hein A. Circulating micro-RNAs as potential blood-based markers for early stage breast cancer detection. PLoS One. 2012;7:e29770.

6. Shimomura A, Shiino S, Kawauchi J, Takizawa S, Sakamoto H, Matsuzaki J, Ono M, Takeshita F, Niida S, Shimizu C. Novel combination of serum microRNA for detecting breast cancer in the early stage. Cancer Sci. 2016; 107:326-34.

7. Wang X, Fang L. Advances in circular RNAs and their roles in breast cancer. J Exp Clin Cancer Res. 2018;37:206.

8. Bartel DP. MicroRNAs: target recognition and regulatory functions. Cell. 2009;136:215-33

9. Yan R, Yang T, Zhai H, Zhou Z, Gao L, Li Y. MicroRNA-150-5p affects cell proliferation, apoptosis, and EMT by regulation of the BRAFV600E mutation in papillary thyroid cancer cells. J Cell Biochem. 2018;119:8763-72.

10. Yang Z, Zhang T, Wang Q, Gao H. Overexpression of microRNA-34a attenuates proliferation and induces apoptosis in pituitary adenoma cells via SOX7. Mol Ther Oncolytics. 2018:10:40-7.

11. Li P, Xie X-B, Chen Q, Pang G-L, Luo W, Tu J-C, Zheng F, Liu S-M, Han L, Zhang J-K. MiRNA-15a mediates cell cycle arrest and potentiates apoptosis in breast cancer cells by targeting synuclein-gamma. Asian Pac J Cancer Prev. 2014;15:6949-54.

12. Xiao R, Li C, Chai B. miRNA-144 suppresses proliferation and migration of colorectal cancer cells through GSPT1. Biomed Pharmacother. 2015:74:138-44.

13. Carreras-Badosa G, Bonmatí A, Ortega F-J, Mercader J-M, Guindo-Martínez M, Torrents D, Prats-Puig A, Martinez-Calcerrada J-M, Platero-Gutierrez E, De Zegher F. Altered circulating miRNA expression profile in pregestational and gestational obesity. J Clin Endocrinol Metab. 2015;100:E1446-56.

14. Trionfini P, Benigni A, Remuzzi G. MicroRNAs in kidney physiology and disease. Nat Rev Nephrol. 2015:11:23.

15. Mao Y, Wei F, Wei C, Wei C. microRNA-574 inhibits cell proliferation and invasion in glioblastoma multiforme by directly targeting zinc finger E-boxbinding homeobox 1. Mol Med Rep. 2018;18:1826-34.

16. Xia X, Li Y, Wang W, Tang F, Tan J, Sun L, Li Q, Sun L, Tang B, He S. MicroRNA-1908 functions as a glioblastoma oncogene by suppressing PTEN tumor suppressor pathway. Mol Cancer. 2015;14:154.

17. Lian D, Wang Z, Liu N. MicroRNA-1908 is a biomarker for poor prognosis in human osteosarcoma. Eur Rev Med Pharmacol Sci. 2016;20:1258-62.

18. Jin J-C, Jin X-L, Zhang X, Piao Y-S, Liu S-P. Effect of OSW-1 on microRNA expression profiles of hepatoma cells and functions of novel microRNAs. Mol Med Rep. 2013;7:1831-7.

19. Chai Z, Fan H, Li Y, Song L, Jin X, Yu J, Li Y, Ma C, Zhou R. miR-1908 as a novel prognosis marker of glioma via promoting malignant phenotype and modulating SPRY4/RAF1 axis. Oncol Rep. 2017;38:2717-26.

20. HAIQIU \& LIAO. microRNA-32 induces radioresistance by targeting DAB2IP and regulating autophagy in prostate cancer cells. Oncol Lett. 2015;10:2055. 
21. Kim S, Woo SM, Min K-J, Seo SU. WP1130 enhances TRAlL-induced apoptosis through USP9X-dependent miR-708-mediated downregulation of c-FLIP. Cancers. 2019;11:344.

22. Zhang L, Li X, Lin X, Wu M. Nerve growth factor promotes the proliferation of Müller cells co-cultured with internal limiting membrane by regulating cell cycle via Trk-A/PI3K/Akt pathway. BMC Ophthalmol. 2019;19:1.

23. Agarwal V, Bell GW, Nam J-W, Bartel DP. Predicting effective microRNA target sites in mammalian mRNAs. elife. 2015;4:e05005.

24. Garcia DM, Baek D, Shin C, Bell GW, Grimson A, Bartel DP. Weak seedpairing stability and high target-site abundance decrease the proficiency of Isy-6 and other microRNAs. Nat Struct Mol Biol. 2011;18:1139.

25. Grimson A, Farh KK-H, Johnston WK, Garrett-Engele P, Lim LP, Bartel DP. MicroRNA targeting specificity in mammals: determinants beyond seed pairing. Mol Cell. 2007;27:91-105.

26. Lewis $B P$, Burge $C B$, Bartel DP. Conserved seed pairing, often flanked by adenosines, indicates that thousands of human genes are microRNA targets. Cell. 2005;120:15-20.

27. Tang Z, Li C, Kang B, Gao G, Li C, Zhang Z. GEPIA: a web server for cancer and normal gene expression profiling and interactive analyses. Nucleic Acids Res. 2017;45:W98-W102.

28. Nagy Á, Lánczky A, Menyhárt O, Győrffy B. Validation of miRNA prognostic power in hepatocellular carcinoma using expression data of independent datasets. Sci Rep. 2018;8:9227.

29. Dell'Orso S, Ganci F, Strano S, Blandino G, Fontemaggi G. ID4: a new player in the cancer arena. Oncotarget. 2010;1:48.

30. Mauel S, Kruse B, Etschmann B, von der Schulenburg AG, Schaerig M, Stövesand K, Wilcken B, Sterner-kock A. Latent transforming growth factor binding protein 4 (LTBP-4) is downregulated in human mammary adenocarcinomas in vitro and in vivo. Apmis. 2007;115:687-700.

31. Lu Y, Li Y, Wang Z, Xie S, Wang Q, Lei X, Ruan Y, Li J. Downregulation of RGMA by HIF-1A/miR-210-3p axis promotes cell proliferation in oral squamous cell carcinoma. Biomed Pharmacother. 2019;112:108608.

32. Yang J, Han F, Liu W, Chen H, Hao X, Jiang X, Yin L, Huang Y, Cao J, Zhang H. ALX4, an epigenetically down regulated tumor suppressor, inhibits breast cancer progression by interfering Wnt/ß-catenin pathway. J Exp Clin Cancer Res. 2017;36:170

33. Zhang Y, Yuan Y, Liang P, Guo X, Ying Y, Shu X-S, Gao M, Cheng Y. OSR1 is a novel epigenetic silenced tumor suppressor regulating invasion and proliferation in renal cell carcinoma. Oncotarget. 2017:8:30008.

34. Cai K, Li T, Guo L, Guo H, Zhu W, Yan L, Li F. Long non-coding RNA LINC00467 regulates hepatocellular carcinoma progression by modulating miR-9-5p/PPARA expression. Open Biol. 2019;9:190074.

\section{Publisher's Note}

Springer Nature remains neutral with regard to jurisdictional claims in published maps and institutional affiliations.

Ready to submit your research? Choose BMC and benefit from:

- fast, convenient online submission

- thorough peer review by experienced researchers in your field

- rapid publication on acceptance

- support for research data, including large and complex data types

- gold Open Access which fosters wider collaboration and increased citations

- maximum visibility for your research: over $100 \mathrm{M}$ website views per year

At $\mathrm{BMC}$, research is always in progress.

Learn more biomedcentral.com/submissions 